\title{
Physical activity and sedentary behaviour of ambulatory older adults in a developed Asian community: a cross- sectional study
}

\author{
Lok Pui $\underline{\mathrm{Ng}}^{1,2}$, MMed, FCFPS, Yi Ling Eileen $\underline{K o h}^{1}$, BSc, Ngiap Chuan $\underline{\operatorname{Tan}}{ }^{1,2}$, MMed, FCFPS
}

\begin{abstract}
INTRODUCTION Physical activity (PA) and sedentary behaviour (SB) independently influence the health outcomes of older adults. Both provide interventional opportunities for successful ageing. We aimed to determine levels of PA and SB in ambulatory older adults and their associated factors in a developed Asian population known for its longevity. METHODS We conducted a cross-sectional observational study in a Singapore public primary healthcare centre. Multi-ethnic Asian adults aged $\geq 60$ years took an interviewer-administered questionnaire survey. PA and SB were assessed using the Physical Activity Scale for the Elderly (PASE; score range 0 to $>400$ ) and the Sedentary Behaviour Questionnaire for the Elderly, respectively.

RESULTS Among 397 participants (50.9\% female; $73.2 \%$ Chinese; $47.9 \%$ aged $\geq 70$ years; $33.5 \%$ employed, including voluntary work), $58.7 \%$ had $\geq 3$ chronic illnesses and $11.1 \%$ required walking aids. The median PASE score was 110.8 (interquartile range 73.8-171.6) and decreased significantly with increasing age. Higher PASE score was associated with higher educational level, employment, independent ambulation without aid, and fewer chronic illnesses $(p<0.01)$. Employment status significantly influenced PASE score $(\beta=84.9,95 \%$ confidence interval $[\mathrm{Cl}] 66.5-103.4 ; p<0.01)$. $37.0 \%$ spent $\geq 8$ hours daily on sedentary activity and were twice as likely to do so if they were employed (odds ratio $2.19,95 \% \mathrm{Cl} 1.34-3.59 ; \mathrm{p}<0.01$ ).

CONCLUSION The PA of the older adults decreased with increasing age and increased with employment. One-third of them were sedentary for $\geq 8$ hours daily. Those who were employed were twice as likely to have SB.
\end{abstract}

Keywords: older adult, physical activity, sedentary behaviour

\section{INTRODUCTION}

The health benefits of physical activity (PA) have been widely documented. ${ }^{(1,2)}$ It is associated with physical, psychological and cognitive benefits, including decelerated declines in age-related physical function as well as reduced risk of dementia and depression among older adults. ${ }^{(1,2)} \mathrm{PA}$ is defined as any bodily movement produced by skeletal muscles that require energy expenditure through playing, working, active transportation, household chores and recreational activities. ${ }^{(3)}$ Exercise is only one subcategory of physical activity. Assessing the entire spectrum of PA (leisure time, occupational, transportation and household chores) provides more comprehensive insight into an individual's health, especially that of older adults, for whom light housework was shown to form the bulk of their total daily PA. ${ }^{(4,5)}$ Low PA refers to inadequate performance of moderate-intensity and vigorous-intensity PA. ${ }^{(6)}$

Low PA differs from sedentary behaviour (SB). SB is defined as waking behaviour characterised by an energy expenditure of five metabolic equivalents (METs) or less while in a sitting or reclining posture. Most studies have used television viewing, sitting and screen time as measures for SB. ${ }^{(7)} \mathrm{SB}$ is associated with adverse health outcomes that are independent of one's level of PA. ${ }^{(8-12)} \mathrm{A}$ recent meta-analysis concluded that prolonged television viewing was associated with increased risk of Type 2 diabetes mellitus and cardiovascular diseases. ${ }^{(8)} \mathrm{SB}$ among the older population is a worldwide problem. A systematic review on the prevalence of SB in older adults showed that $55 \%$ reported watching more than two hours of television daily, while $60 \%$ of older adults reported sitting for more than four hours daily. ${ }^{(7)}$

The phenomenon of frailty, which is concurrent with ageing, has received increasing attention around the world in recent years. Frailty increases the vulnerability of older adults following trivial stressor events and leads to a higher risk of adverse health-related outcomes. ${ }^{(13)}$ Sedentary older adults were more likely to be frail, according to a landmark study by Fried et al. ${ }^{(14)}$ Furthermore, low PA was independently associated with frailty and adverse health outcomes in these older adults. ${ }^{(14)}$ As both PA and SB are modifiable, this offers opportunities for intervention to reduce the risk of frailty.

Singapore has a highly urbanised but rapidly ageing Asian population. In view of the spiralling socioeconomic burden and healthcare cost in managing older adults, the local government has invested in infrastructure, community facilities and social engineering to promote healthy living for the older population. ${ }^{(15)}$ Nevertheless, despite the country's high World Health Organization longevity ranking among developed nations, ${ }^{(16)} 6.2 \%$ of the local older population aged 65 years and older were known to be frail. ${ }^{(17)}$ Measurements of their PA, SB and associated factors will thus provide insights into their susceptibility to frailty and health status. To the best of our knowledge, there is no existing study on

${ }^{1}$ SingHealth Polyclinics, ${ }^{2}$ Family Medicine Academic Clinical Programme, SingHealth Duke-NUS Academic Medical Centre, Singapore

Correspondence: Dr Ng Lok Pui, Family Physician, Heartbeat@Bedok, 11 Bedok North Street 1, \#02-01/\#03-01, Singapore 469662.ng.lok.pui@singhealth.com.sg 
PA and SB among older adults in Singapore. This study aimed to determine the levels of PA and SB among ambulatory older Asian persons dwelling in the community and associated factors.

\section{METHODS}

A cross-sectional, interviewer-administered questionnaire survey was conducted in a local public primary care centre (i.e. a polyclinic) in Singapore from December 2016 to June 2017. The polyclinic, located in the southeastern region of the islandstate, served 285,000 multi-ethnic Asian residents in 2015, in an estate that has the largest population of older residents $(31,600)$ in Singapore. ${ }^{(18)}$

The inclusion criteria were: (a) aged $\geq 60$ years; (b) community mobile or ambulatory with or without walking aids (e.g. walking sticks) or assisted by a caregiver, excluding those on walking frames or wheelchairs; and (c) able to provide written informed consent. Participants who could not converse in or understand English, Malay or Mandarin were excluded from the study, as the translated questionnaire was only available in these three languages.

The sample size was calculated based on previous local study findings on PA among older people $(40.2 \%$ did not exercise at all in that study) with $5 \%$ precision and $95 \%$ confidence interval (Cl). ${ }^{(19)}$ The required sample size was 370 . It was increased to 400 participants to buffer for missing or incomplete data. Stratified sampling based on age and according to the demographics of the clinic's attendance was used to avoid over- or under-representing any age groups.

Before the commencement of the study, research assistants were trained to standardise questionnaire administration. These research assistants screened potential participants based on the study enrolment eligibility and provided study-related information at the health monitoring station within the polyclinic. They clarified any doubts with participants before obtaining their informed consent. Each enrolled participant was reimbursed a token of SGD 5 upon completion of the questionnaire.

PA was measured using the original English version of the Physical Activity Scale for the Elderly (PASE) developed by Washburn. ${ }^{(4)}$ The PASE assesses the level of PA of communitydwelling older adults based on three domains: leisure time, household and work-related activities, and ranges from 0 to $>400$. It was selected for its good test-retest reliability with an intraclass correlation coefficient of 0.75 . The total PASE score was computed through multiplying the amount of time spent in each activity (hours per day over the past seven-day period) by the respective weights and summing up the scores of all the activities. The Malay and Chinese versions of the PASE had been validated in Malaysia and Hong Kong, respectively, ${ }^{(5,20)}$ and were used for participants who only understood Malay or Chinese.

SB was assessed using the Sedentary Behaviour Questionnaire for the Elderly (SBQE) developed by $\mathrm{Ku}$ et al. ${ }^{(21)}$ The SBQE measures the time spent in different types of sedentary activities among ambulatory older persons in the community. It has good validity with significant correlation between self-reported total sedentary time and accelerometerderived sedentary time $(\rho=0.52, p<0.001)$, with good test- retest reliability of $\rho=0.74$. The study questionnaire also collected data on participants' demographic profile as well as barriers to and motivators for PAs.

Ethical approval for the study was obtained from the SingHealth Centralised Institutional Review Board (CIRB Ref 2016/2970). Data was audited and analysed using IBM SPSS Statistics version 24.0 (IBM Corp, Armonk, NY, USA). PASE scores were computed according to the PASE user manual. Basic descriptive statistics on participants' demographic and clinical characteristics were presented in frequencies and percentages. PASE scores were presented as median with interquartile range (IQR). Mann-Whitney $U$ test or Kruskal-Wallis test were used to compare the median PASE scores of participants with different characteristics. Spearman correlation was used to assess the PASE score and number of chronic conditions. Multiple regression was performed to determine the factors associated with PASE scores. Overall SB was categorised based on overall time spent in sedentary activity ( $<8$ hours or $\geq 8$ hours daily). Comparisons between these categories were performed using chi-square test and Mann-Whitney $U$ test for univariate analysis and logistic regression for multivariate analysis. A p-value $<0.05$ was considered to be significant.

\section{RESULTS}

A total of 400 older persons were recruited, of whom three were repeat participants. Data from the remaining 397 participants was analysed after excluding these duplicates. The demographic and clinical characteristics of the participants are presented in Table I. $50.9 \%$ of them were female. The ethnic distribution was $73.2 \%$ Chinese, $19.6 \%$ Malay, $5.9 \%$ Indian and $1.3 \%$ others. $47.9 \%$ of the participants were aged $\geq 70$ years. $79.0 \%$ had up to secondary education and $33.5 \%$ of them were employed (including voluntary work). More than half (58.7\%) had $\geq 3$ chronic medical conditions. The majority of the participants had no falls in the past one year and were able to ambulate without a walking stick or assistance from their caregiver $(78.3 \%$ and $88.9 \%$, respectively). $71.3 \%$ of them had a body mass index $\geq 23 \mathrm{~kg} / \mathrm{m}^{2}$.

The median PASE score was 110.8 (IQR 73.8-171.6) and decreased significantly with increasing age $(p<0.01)$. Higher PASE score was associated with higher educational level, employment, independent ambulation without aid, and fewer chronic illnesses $(p<0.01)$. Employment status significantly influenced PASE score $(\beta=84.9 ; 95 \% \mathrm{Cl} 66.5-103.4 ; \mathrm{p}<0.01)$ in the multivariate analysis (Table II).

The total median daily sedentary time was 6.6 hours. $147(37.0 \%)$ participants had $\geq 8$ sedentary hours daily and $250(63.0 \%)$ had $<8$ sedentary hours. SB was significantly associated with employment, with those who were employed being twice more likely to have $\geq 8$ hours of SB daily (odds ratio [OR] 2.19, 95\% Cl 1.34-3.59; p < 0.01) (Table III).

\section{DISCUSSION}

The median PASE score in the local study population was higher than equivalent scores reported in the literature for older persons 
Table I. Baseline characteristics of the study participants $(n=397)$.

\begin{tabular}{|c|c|}
\hline Characteristic & No. (\%)/mean (range) \\
\hline \multicolumn{2}{|l|}{ Age (yr) } \\
\hline$\geq 70$ & $190(47.9)$ \\
\hline$<70$ & $207(52.1)$ \\
\hline \multicolumn{2}{|l|}{ Gender } \\
\hline Female & $202(50.9)$ \\
\hline Male & $195(49.1)$ \\
\hline \multicolumn{2}{|l|}{ Ethnicity* } \\
\hline Non-Chinese & $105(26.8)$ \\
\hline Chinese & $287(73.2)$ \\
\hline \multicolumn{2}{|l|}{ Education* } \\
\hline University/post-tertiary & $20(5.1)$ \\
\hline No formal education & $42(10.6)$ \\
\hline Primary & $114(28.8)$ \\
\hline Secondary & $157(39.6)$ \\
\hline High school/diploma & $63(15.9)$ \\
\hline \multicolumn{2}{|l|}{ Employment status } \\
\hline Unemployed & $264(66.5)$ \\
\hline Employed $^{+}$ & $133(33.5)$ \\
\hline \multicolumn{2}{|l|}{ Current housing type } \\
\hline Private residence/others & $60(15.1)$ \\
\hline Public housing & $337(84.9)$ \\
\hline \multicolumn{2}{|l|}{ Home ownership* } \\
\hline Rented & $25(6.3)$ \\
\hline Self owned & $369(93.7)$ \\
\hline \multicolumn{2}{|l|}{ Marital status } \\
\hline Divorced/separated & $16(4.0)$ \\
\hline Married & $294(74.1)$ \\
\hline Single & $27(6.8)$ \\
\hline Widowed & $60(15.1)$ \\
\hline \multicolumn{2}{|l|}{ Living situation* } \\
\hline With someone/at nursing home & $344(86.9)$ \\
\hline Alone & $52(13.1)$ \\
\hline \multicolumn{2}{|l|}{ Fall in last 1 yr? } \\
\hline No & $311(78.3)$ \\
\hline Yes & $86(21.7)$ \\
\hline \multicolumn{2}{|l|}{ Walking aid? } \\
\hline No & $353(88.9)$ \\
\hline Yes & $44(11.1)$ \\
\hline No. of chronic conditions & $3(2-3)$ \\
\hline \multicolumn{2}{|l|}{ Body mass index $\left(\mathrm{kg} / \mathrm{m}^{2}\right)$} \\
\hline$<23$ & $114(28.7)$ \\
\hline$\geq 23$ & $283(71.3)$ \\
\hline
\end{tabular}

*Missing data was excluded from the analysis. IIncluding non-paid voluntary work.

in North America, ${ }^{(4)}$ Hong Kong(20) and Malaysia, ${ }^{(5)}$ but lower than those in Japan. ${ }^{(22)}$ The score was closer to those of ambulant older persons in the Taiwanese community who had similar demographic characteristics and employment rates (Taiwan $31.3 \%$ vs. Singapore $34.3 \%)$. $^{(23,24)}$

The present study showed that employment, including voluntary or non-paid jobs, was associated with higher PASE scores. Travelling to and returning from workplaces often involves walking for those who use public transport. Singapore is among the most expensive places in the world to drive private vehicles due to high taxes on car ownership. This is aligned to the national transport policy of encouraging wider use of public transport to curb air pollution from vehicle exhaust and traffic congestion. ${ }^{(25)}$ Labour laws have also been revised to increase the minimal retirement age from 62 years in 2016 to 67 years in July 2017.(26) Even those who reach the official retirement age may extend their employment on a short-term contract basis. Concurrently, there have been official measures to promote volunteerism in the population, targeting retired or semi-retired older adults. Aside from optimising human resources in a rapidly ageing population, these measures may directly or indirectly raise levels of PA.

Nonetheless, some occupations can be inherently sedentary, including those who work as office-based administrators, professional drivers and cashiers. Singapore's Health Promotion Board (HPB) has partnered local employers to develop Healthy Workplace Ecosystems for their employees, including the provision of free or subsidised access to gymnasiums within or proximal to their workplaces. However, the scale of adoption seems confined to larger enterprises, and access may not be extended to part-time employees, of whom a significant proportion are older workers. Whether older employees actively participate in these programmes and gain health benefits has yet to be objectively evaluated.

A local survey showed that $95 \%$ of the local population own a smartphone and $53 \%$ use it to stream television or movie content. ${ }^{(27)}$ The widespread availability of televisions in households and video streaming via mobile phones and devices makes media readily available everywhere at any time. This is likely to aggravate the SB of the elderly, who are generally fond of this pastime. The local government has implemented measures to mitigate SB, investing in infrastructure development to build $300 \mathrm{~km}$ of nationwide park connectors. Such facilities near residences are intended to encourage cycling, jogging and walking, which are forms of PA that older residents prefer.

More specific measures targeting older persons include offering free or heavily subsidised exercise programmes at local community centres located within each housing estate. HPB has also launched a community-based programme in 2017 promoting seven sit-down exercises to help older persons maintain an active lifestyle. ${ }^{(28)}$ These exercises help to improve strength, balance and flexibility, as well as helping to curb sedentary behaviour in both domiciliary and workplace settings.

Other factors influencing PA, correlating with higher PASE scores, included higher educational level, independent ambulation without aid, and fewer chronic illnesses. It is possible that more highly educated participants are more aware of the benefits of PA and adopt a more active lifestyle, but further study is needed to support this hypothesis. More resources should also be directed at supporting vulnerable older persons to avert the inverse care law, ${ }^{(29)}$ including designing PA programmes that are targeted at older adults with lower educational status and those 
Table II. Association between the demographic characteristics of older adults and their PASE scores.

\begin{tabular}{|c|c|c|c|c|}
\hline Characteristic & Median (IQR) & p-value & $\operatorname{Adj} \beta(95 \% \mathrm{Cl})$ & p-value \\
\hline Age (yr) & & $<0.01^{\S}$ & & \\
\hline$\geq 70$ & $93.3(53.4-138.7)$ & & Reference & \\
\hline$<70$ & $135.8(97.6-196.5)$ & & $15.2(-3.2$ to 33.6$)$ & 0.10 \\
\hline Gender & & 0.35 & & \\
\hline Female & $110.8(70.0-165.3)$ & & Reference & \\
\hline Male & $110.9(75.1-178.6)$ & & $8.7(-8.3$ to 25.8$)$ & 0.31 \\
\hline Ethnicity* & & 0.398 & & \\
\hline Non-Chinese & $112.7(82.7-176.5)$ & & Reference & \\
\hline Chinese & $110.8(67.6-173.5)$ & & $-10.6(-29.3$ to 8.0$)$ & 0.26 \\
\hline Education* & & $<0.01^{\S}$ & & \\
\hline University/post-tertiary & $142.0(92.1-167.5)$ & & Reference & \\
\hline No formal education & $72.5(50.0-111.0)$ & & $-10.0(-57.4$ to 37.5$)$ & 0.68 \\
\hline Primary & $112.5(77.8-166.8)$ & & $-3.0(-43.7$ to 37.7$)$ & 0.88 \\
\hline Secondary & $114.6(71.3-178.6)$ & & $3.3(-36.4$ to 42.9$)$ & 0.87 \\
\hline High school/diploma & $129.3(93.1-186)$ & & $-5.3(-47.1$ to 36.5$)$ & 0.80 \\
\hline Employment status & & $<0.01^{\S}$ & & \\
\hline Unemployed & $97.4(61.3-133.2)$ & & Reference & \\
\hline Employed $^{\dagger}$ & $178.1(115.9-258.3)$ & & 84.9 (66.5 to 103.4$)$ & $<0.01^{\S}$ \\
\hline Current housing type & & 0.47 & & \\
\hline Private residence/others & $120.8(88.3-180.4)$ & & Reference & \\
\hline Public housing & $110.4(72.7-171.6)$ & & $-17.0(-40.9$ to 6.9$)$ & 0.16 \\
\hline Home ownership* & & 0.74 & & \\
\hline Rented & $135.8(63.9-218.1)$ & & Reference & \\
\hline Self owned & $110.8(74.6-171.6)$ & & $-1.2(-34.7$ to 32.3$)$ & 0.95 \\
\hline Marital status & & 0.03 & & \\
\hline Divorced/separated & $127.8(92.5-176.6)$ & & Reference & \\
\hline Married & $113.6(75.1-177.9)$ & & $14.5(-29.6$ to 58.5$)$ & 0.52 \\
\hline Single & $147.8(77.9-226.1)$ & & $26.3(-23.5$ to 76$)$ & 0.30 \\
\hline Widowed & $97.2(53.1-128.7)$ & & $19.0(-27.0$ to 65.0$)$ & 0.42 \\
\hline Living situation* & & 0.67 & & \\
\hline With someone/at nursing home & $107.2(77.6-147.3)$ & & Reference & \\
\hline Alone & $112.5(72.5-177.1)$ & & $3.5(-24.5$ to 31.4$)$ & 0.81 \\
\hline Fall in last 1 year? & & 0.20 & & \\
\hline No & $113.8(77.5-171.7)$ & & Reference & \\
\hline Yes & $101.4(65.0-173.0)$ & & $-5.0(-24.0$ to 14.1$)$ & 0.61 \\
\hline Walking aid? & & $<0.01^{\S}$ & & \\
\hline No & $116.7(77.7-178.6)$ & & Reference & \\
\hline Yes & $77.3(50.0-108.1)$ & & $-20.4(-47.0$ to 6.3$)$ & 0.13 \\
\hline No. of chronic conditions ${ }^{\ddagger}$ & -0.19 & $<0.01^{\S}$ & $-5.5(-12.9$ to 1.9$)$ & 0.14 \\
\hline Body mass index $\left(\mathrm{kg} / \mathrm{m}^{2}\right)$ & & 0.32 & & \\
\hline$<23$ & $118.7(78.3-176.5)$ & & Reference & \\
\hline$\geq 23$ & $108.3(70.1-168.6)$ & & $-10.2(-28.0$ to 7.6$)$ & 0.26 \\
\hline
\end{tabular}

*Missing data was excluded from the analysis. Including non-paid voluntary work. $\neq$ Calculated using Mann-Whitney $U$ test. $\S p<0.05$ was considered statistically significant. Adj $\beta$ : adjusted beta coefficient; Cl: confidence interval; IQR: interquartile range; PASE: Physical Activity Scale for the Elderly

who require walking aids. Ultimately, the goal of these multipronged measures to reduce SB and increase PA is to decrease the frailty risks of older adults, so that they remain independent and healthy in the community.

This study was not without limitations. It provides insights into the PA and SB status of an expanding ageing population with increasing longevity. This group of community-dwelling older adults constitutes a large proportion of the local geriatric population. From a health economics perspective, resources and effort should be devoted to keeping them healthy in the community. Although multifaceted interventions will likely be needed to address the PA and SB of these older persons, a randomised controlled trial approach to prove the effectiveness of such interventions would be confounded by existing nationwide 
Table III. Association between the demographic characteristics of the older adults and their levels of sedentary behaviour (SB).

\begin{tabular}{|c|c|c|c|c|c|}
\hline \multirow[t]{2}{*}{ Characteristic } & \multicolumn{2}{|c|}{ No. (\%)/mean (range) } & \multirow[t]{2}{*}{ p-value } & \multirow[t]{2}{*}{ Adjusted OR (95\% CI) } & \multirow[t]{2}{*}{ p-value } \\
\hline & SB $<8 \mathrm{hr}$ & $S B \geq 8 \mathrm{hr}$ & & & \\
\hline Age (yr) & & & $<0.01^{\ddagger}$ & & \\
\hline$\geq 70$ & $133(70.0)$ & $57(30.0)$ & & Reference & \\
\hline$<70$ & $117(56.5)$ & $90(43.5)$ & & $1.24(0.75-2.06)$ & 0.41 \\
\hline Gender & & & 0.16 & & \\
\hline Female & $134(66.3)$ & $68(33.7)$ & & Reference & \\
\hline Male & $116(59.5)$ & $79(40.5)$ & & $1.28(0.79-2.05)$ & 0.31 \\
\hline Ethnicity* & & & 0.36 & & \\
\hline Non-Chinese & $62(59.0)$ & $43(41.0)$ & & Reference & \\
\hline Chinese & $184(64.1)$ & $103(35.9)$ & & $0.76(0.46-1.28)$ & 0.30 \\
\hline Education* & & & 0.08 & & \\
\hline University/post-tertiary & $11(55.0)$ & $9(45.0)$ & & Reference & \\
\hline No formal education & $31(73.8)$ & $11(26.2)$ & & $0.65(0.17-2.39)$ & 0.51 \\
\hline Primary & $78(68.4)$ & $36(31.6)$ & & $0.5(0.17-1.51)$ & 0.22 \\
\hline Secondary & $97(61.8)$ & $60(38.2)$ & & $0.62(0.21-1.79)$ & 0.38 \\
\hline High school/diploma & $32(50.8)$ & $31(49.2)$ & & $0.93(0.31-2.83)$ & 0.90 \\
\hline Employment status & & & $<0.01^{\ddagger}$ & & \\
\hline Unemployed & $186(70.5)$ & $78(29.5)$ & & Reference & \\
\hline Employed $^{+}$ & $64(48.1)$ & $69(51.9)$ & & $2.19(1.34-3.59)$ & $<0.01^{\ddagger}$ \\
\hline Current housing type & & & 0.82 & & \\
\hline Private residence/others & $37(61.7)$ & $23(38.3)$ & & Reference & \\
\hline Public housing & $213(63.2)$ & $124(36.8)$ & & $0.89(0.46-1.73)$ & 0.73 \\
\hline Home ownership* & & & 0.89 & & \\
\hline Rented & $16(64.0)$ & $9(36.0)$ & & Reference & \\
\hline Self owned & $231(62.6)$ & $138(37.4)$ & & $1.14(0.46-2.85)$ & 0.78 \\
\hline Marital status & & & 0.40 & & \\
\hline Divorced/separated & $9(56.3)$ & $7(43.8)$ & & Reference & \\
\hline Married & $183(62.2)$ & $111(37.8)$ & & $1.14(0.35-3.79)$ & 0.83 \\
\hline Single & $15(55.6)$ & $12(44.4)$ & & $1.10(0.29-4.19)$ & 0.89 \\
\hline Widowed & $43(71.7)$ & $17(28.3)$ & & $0.77(0.22-2.71)$ & 0.68 \\
\hline Living situation* & & & 0.25 & & \\
\hline With someone/at nursing home & $220(64)$ & $124(36)$ & & Reference & \\
\hline Alone & $29(55.8)$ & $23(44.2)$ & & $1.66(0.77-3.58)$ & 0.20 \\
\hline Fall in last 1 yr? & & & 0.59 & & \\
\hline No & $198(63.7)$ & $113(36.3)$ & & Reference & \\
\hline Yes & $52(60.5)$ & $34(39.5)$ & & $1.17(0.69-1.98)$ & 0.56 \\
\hline Walking aid? & & & $0.02^{\ddagger}$ & & \\
\hline No & $215(60.9)$ & $138(39.1)$ & & Reference & \\
\hline Yes & $35(79.5)$ & $9(20.5)$ & & $0.61(0.27-1.40)$ & 0.24 \\
\hline No. of chronic conditions & $3.0(2.0-3.0)$ & $3.0(2.0-3.0)$ & 0.16 & $0.95(0.78-1.17)$ & 0.65 \\
\hline Body mass index $\left(\mathrm{kg} / \mathrm{m}^{2}\right)$ & & & 0.61 & & \\
\hline$<23$ & 74 (64.9) & $40(35.1)$ & & Reference & \\
\hline$\geq 23$ & $176(62.2)$ & $107(37.8)$ & & $1.11(0.68-1.83)$ & 0.68 \\
\hline
\end{tabular}

*Missing data was excluded from the analysis. Including non-paid voluntary work. $\neq \mathrm{p}<0.05$ was considered statistically significant. Cl: confidence interval; OR: odds ratio

programmes in Singapore. Serial surveys may be an alternative method to assess their lifestyle status.

Self-reported data by study participants using scales has inherent limitations, such as recall bias and accuracy. In spite of this limitation and potential under-reporting, the results gave an estimated magnitude of the activity status of older adults and identified opportunities for interventions to enhance their PA and reduce their SB. With more local older persons using smartphones with an in-built PA tracker function, their PA can be more objectively assessed. The National Steps Challenge is also conducive for this modality of measurement, as participants are provided with free digital tracker wearables, although such 
devices have yet to comprehensively measure PA. ${ }^{(30)}$ Objective assessment of SB is more challenging, but rapidly advancing technology may offer possible solutions in the future.

Additionally, our study population comprised ambulatory older persons who were able to access the polyclinic, while those who sought medical consultations with other healthcare providers in the community were excluded. Generalisability of the results to the general geriatric population is thus restricted.

In conclusion, the median PA score of 110.8 among ambulatory older persons in this study was comparable to that of other Asian developed communities. Factors associated with lower PA included education, comorbidity and employment status. The duration of their SB covered at least a quarter of each day, excluding sleep hours. Promoting PA among older persons should start early, when they have fewer morbidities. This may help them to stay in employment longer, as being employed was found to be positively associated with their level of PA. In addition, efforts to educate and remind older persons to reduce their sedentary hours are just as important, including those who are employed.

\section{ACKNOWLEDGEMENTS}

The authors would like to thank the staff at the study site, Patricia, Caris, Syarafina and Usha from the Department of Research at SingHealth Polyclinics, for providing project management support for the study. The authors are also grateful to the nursing students from Ngee Ann Polytechnic and Mr John Yap, medical student from NUS Yong Loo Lin School of Medicine, for executing the questionnaire survey and collating the data. This research was supported by seed funding from the SingHealth Polyclinics Research Support Programme (SHP-SEED 36-2016 [5]).

\section{REFERENCES}

1. Sattelmair JR, Pertman JH, Forman DE. Effects of physical activity on cardiovascular and noncardiovascular outcomes in older adults. Clin Geriatr Med 2009; 25:677-702.

2. Ratey JJ, Loehr JE. The positive impact of physical activity on cognition during adulthood: a review of underlying mechanisms, evidence and recommendations. Rev Neurosci 2011; 22:171-85.

3. World Health Organization. Physical activity. Available at: http://www.who. int/topics/physical_activity/en/. Accessed May 15, 2018.

4. Washburn RA, Smith KW, Jette AM, Janney CA. The Physical Activity Scale for the Elderly (PASE): development and evaluation. J Clin Epidemiol 1993; 46:153-62.

5. Ismail N, Hairi F, Choo WY, et al. The Physical Activity Scale for the Elderly (PASE): validity and reliability among community-dwelling older adults in Malaysia. Asia Pac J Public Health 2015; 27(8 Suppl):62S-72S.

6. Tremblay MS, Aubert S, Barnes JD, et al. Sedentary Behavior Research Network (SBRN) - Terminology Consensus Project process and outcome. Int J Behav Nutr Phys Act 2017; 14:75.

7. Harvey JA, Chastin SF, Skelton DA. Prevalence of sedentary behavior in older adults: a systematic review. Int J Environ Res Public Health 2013; 10:6645-61.

8. Grøntved A, Hu FB. Television viewing and risk of type 2 diabetes, cardiovascular disease, and all-cause mortality: a meta-analysis. JAMA 2011; 305:2448-55.
9. Kronenberg F, Pereira MA, Schmitz MK, et al. Influence of leisure time physical activity and television watching on atherosclerosis risk factors in the NHLBI Family Heart Study. Atherosclerosis 2000; 153:433-43.

10. Salmon J, Bauman A, Crawford D, Timperio A, Owen N. The association between television viewing and overweight among Australian adults participating in varying levels of leisure-time physical activity. Int J Obes Relat Metab Disord 2000; 24:600-6.

11. Brown WJ, Miller YD, Miller R. Sitting time and work patterns as indicators of overweight and obesity in Australian adults. Int J Obes Relat Metab Disord 2003; 27:1340-6.

12. van der Ploeg HP, Chey T, Korda RJ, Banks E, Bauman A. Sitting time and all-cause mortality risk in 222497 Australian adults. Arch Intern Med 2012; 172:494-500.

13. Clegg A, Young J, Iliffe S. Rikkert MO, Rockwood K. Frailty in elderly people. Lancet 2013; 381:752-62.

14. Fried LP, Tangen CM, Walston J; Cardiovascular Health Study Collaborative Research Group. Frailty in older adults: evidence for a phenotype. J Gerontol A Biol Sci Med Sci 2001; 56:M146-56.

15. Health Promotion Board, Singapore. New exercise campaign to encourage active living among seniors, including those with reduced mobility. Available at: https://www.hpb.gov.sg/article/new-exercise-campaign-to-encourage-activeliving-among-seniors-including-those-with-reduced-mobility. Accessed June 26, 2018.

16. World Health Organization. World Health Statistics 2018: monitoring health for the sustainable development goals. Available at: http://apps.who.int/iris/ bitstream/handle/10665/272596/9789241565585-eng.pdf?ua=1. Accessed June 26, 2018.

17. Merchant RA, Chen MZ, Tan LWL, et al. Singapore Healthy Older People Everyday (HOPE) Study: prevalence of frailty and associated factors in older adults. J Am Med Dir Assoc 2017; 18:734.e9-734.e14.

18. Statistics Singapore Newsletter. Geographic Distribution of the Singapore Resident Population. Available at: https://www.singstat.gov.sg/-/media/files/ publications/population/ssnsep10-pg25-29.pdf. Accessed June 26, 2018.

19. Quah JHM, Wang P, Ng RRG, Luo N, Tan NC. Health-related quality of life of older Asian patients with multimorbidity in primary care in a developed nation. Geriatr Gerontol Int 2017; 17:1429-37.

20. Ngai SP, Cheung RT, Lam PL, Chiu JK, Fung EY. Validation and reliability of the Physical Activity Scale for the Elderly in Chinese population. J Rehabil Med 2012; 44:462-5.

21. Ku PW, Sun WJ, Chen LJ. Development of the Sedentary Behavior Questionnaire for the Elderly. Sports Exercise Res 2016; 18:41-55.

22. Hagiwara A, Ito N, Sawai K, Kazuma K. Validity and reliability of the Physical Activity Scale for the Elderly (PASE) in Japanese elderly people. Geriatr Gerontol Int 2008; 8:143-51.

23. Vaughan K, Miller WC. Validity and reliability of the Chinese translation of the Physical Activity Scale for the Elderly (PASE). Disabil Rehabil 2013; 35:191-7.

24. Manpower Research and Statistics Department, Ministry of Manpower, Singapore. A Statistical Profile of Older Workers, Paper No. 2/2007. Available at: http://stats.mom.gov.sg/iMAS_PdfLibrary/mrsd-Stat-profile-older-workers. pdf\#page=10. Accessed May 17, 2018.

25. The Economist Intelligence Unit. Worldwide Cost of Living Report 2018. Available at: http://www.eiu.com/topic/worldwide-cost-of-living. Accessed June 26, 2018.

26. Tan A. Parliament: Singapore to raise re-employment age to 67 from Jul 1, 2017. In: The Business Times [online]. Available at: https://www.businesstimes.com. sg/government-economy/parliament-singapore-to-raise-re-employment-age-to67-from-jul-1-2017. Accessed June 26, 2018.

27. Savvy Singapore: Decoding a digital nation. In: Ernst \& Young [online]. Available at: https://www.ey.com/Publication/vwLUAssets/ey-savvy-singapore-decodinga-digital-nation/\%24FILE/ey-savvy-singapore-decoding-a-digital-nation.pdf. Accessed June 26, 2018.

28. Health Hub, Ministry of Health, Singapore. 7 easy exercises to an active lifestyle (step-by step guide). Available at: https://www.healthhub.sg/programmes/83/ healthy-ageing-exercise-step-by-step-guide. Accessed June 30, 2018.

29. Hart JT. The inverse care law. Lancet 1971; 1:405-12.

30. HealthHub, Ministry of Health, Singapore. National Steps Challenge ${ }^{\text {TM }}$ Season 3. Available at: https://www.healthhub.sg/programmes/37/nsc. Accessed June 30, 2018. 